\title{
Six months supplementation with conjugated linoleic acid induces regional-specific fat mass decreases in overweight and obese
}

\author{
Jean-Michel Gaullier $^{1 *}$, Johan Halse ${ }^{2}$, Hans Olav Høivik ${ }^{3}$, Kjetil Høye ${ }^{3}$, Christian Syvertsen ${ }^{1}$, \\ Minna Nurminiemi ${ }^{1}$, Cecilie Hassfeld ${ }^{1}$, Alexandra Einerhand ${ }^{4}$, Marianne O'Shea ${ }^{4}$ and Ola Gudmundsen ${ }^{1}$ \\ ${ }^{1}$ Link Medical Research AS, Gåsevikveien 8, N-2027 Kjeller, Norway \\ ${ }^{2}$ Diabetes and Overweight Clinic, Pilestredet Park 7, N-0176 Oslo, Norway \\ ${ }^{3}$ Hedmark Medical Center, Grønnegata 54, PO Box 3, N-2303 Hamar, Norway \\ ${ }^{4}$ Lipid Nutrition, division of Loders Croklaan, PO Box 4, 1520 AA, Wormerveer, The Netherlands
}

(Received 31 March 2006 - Revised 23 August 2006 - Accepted 17 October 2006)

\begin{abstract}
Long-term supplementation with conjugated linoleic acid (CLA) reduces body fat mass (BFM) and increases or maintains lean body mass (LBM). However, the regional effect of CLA was not studied. The study aimed to evaluate the effect of CLA per region and safety in healthy, overweight and obese adults. A total of 118 subjects (BMI: $28-32 \mathrm{~kg} / \mathrm{m}^{2}$ ) were included in a double blind, placebo-controlled trial. Subjects were randomised into two groups supplemented with either $3.4 \mathrm{~g} / \mathrm{d}$ CLA or placebo for 6 months. CLA significantly decreased BFM at month $3(\Delta=-0.9 \%$, $P=0.016)$ and at month $6(\Delta=-3.4 \%, P=0.043)$ compared with placebo. The reduction in fat mass was located mostly in the legs $(\Delta=-0.8 \mathrm{~kg}, P<0.001)$, and in women $(\Delta=-1.3 \mathrm{~kg}, P=0.046)$ with BMI $>30 \mathrm{~kg} / \mathrm{m}^{2}(\Delta=-1.9 \mathrm{~kg}, P=0.011)$, compared with placebo. The waist-hip ratio decreased significantly $(P=0.043)$ compared with placebo. LBM increased $(\Delta=+0 \cdot 5 \mathrm{~kg}, P=0 \cdot 049)$ within the CLA group. Bone mineral content was not affected $(P=0 \cdot 70)$. All changes were independent of diet and physical exercise. Safety parameters including blood lipids, inflammatory and diabetogenic markers remained within the normal range. Adverse events did not differ between the groups. It is concluded that supplementation with CLA in healthy, overweight and obese adults decreases BFM in specific regions and is well tolerated.
\end{abstract}

Conjugated linoleic acid: Body composition: Overweight: Obesity

Conjugated linoleic acid (CLA), which refers to a mixture of linoleic acid isomers containing conjugated double bonds, has been shown in animal models to share several potential health benefits including positively influencing body composition, reducing atherosclerosis biomarkers, reducing cancer risk, diabetes management, reducing inflammation and positively influencing the immune response ( $\mathrm{Zu}$ \& Schut, 1992; Cook et al. 1993; Ip et al. 1994; Lee et al. 1994; Miller et al. 1994; Liew et al. 1995; Schonberg \& Krokan, 1995; Wong et al. 1997; Cunningham et al. 1997; Dugan et al. 1997; Nicolosi et al. 1997; Houseknecht et al. 1998; West et al. 1998; DeLany et al. 1999; Park et al. 1999; Gavino et al. 2000; Szymczyk et al. 2001; Rahman et al. 2001; Akahoshi et al. 2002; Corino et al. 2002; Bassaganya-Riera et al. 2003, 2004; Ostrowska et al. 2003; Bhattacharya et al. 2005; Wargent et al. 2005).

In humans, CLA has been tested extensively for its ability to modify body composition (Lowery et al. 1998; Atkinson, 1999; Berven et al. 2000; Blankson et al. 2000; Riserus et al. 2001; Thom et al. 2001; Kreider et al. 2002; Gaullier et al. 2004, 2005). When the studies were performed with reliable body composition measurement methodology (e.g. dual-energy X-ray absorptiometry (DEXA) scan) together with the mixture containing mainly the two bioactive isomers cis-9,trans-11 and trans-10,cis-12 CLA (Gaullier et al. 2002), CLA reduced body fat mass (BFM) in humans at the same time as lean body mass (LBM) was preserved (Gaullier et al. 2004, 2005). However, it was not shown whether BFM was reduced equally in the whole body or if the reduction was restricted to some regions. This finding could be of importance since abdominal obesity has been associated with increased risk of CVD (Reaven, 2005).

Other studies with supplementation of the two bioactive CLA isomers in humans showed that CLA is able to stimulate the immune response (Albers et al. 2003; Song et al. 2005), improves insulin sensitivity in sedentary individuals (Eyjolfson et al. 2004) and beneficially modifies lipid metabolism (Noone et al. 2002). Human studies on type 2 diabetics showed conflicting results (Belury et al. 2000, 2003; Moloney et al. 2004). The reported negative effect on insulin sensitivity in one of the trials with type 2 diabetic patients might, however, have been due to the fact that there was a bias in glucose tolerance between

Abbreviations: AE, adverse event; AFM, fat mass in arms; ALAT, alanine amino transferase; ALP, alkaline phosphatase; ASAT, aspartate amino transferase; BFM, body fat mass; BMC, bone mineral content; CLA, conjugated linoleic acid; CRP, C-reactive protein; DEXA, dual-energy X-ray absorptiometry; HbAlc, glucohaemoglobin; LBM, lean body mass; LFM, fat mass in legs; Lp(a), lipoprotein a; PP, per protocol; TFM, fat mass in abdomen (trunk).

* Corresponding author: Dr J.-M. Gaullier, fax +47.63893211, email j-m@scr.no 
placebo and the CLA group at the start of the trial and not due to CLA intake per se (Moloney et al. 2004). No acute toxic adverse events (AE) were reported in any of the trials. When reported, the $\mathrm{AE}$ were of mild character and were associated mostly with gastrointestinal disturbances (Berven et al. 2000; Blankson et al. 2000; Gaullier et al. 2004, 2005). In another controlled study, the incidence of AE was lower in the CLA-treated group as compared with the control group (Whigham et al. 2004). However, other studies showed that the mixture of the two bioactive isomers of CLA could increase markers of lipid peroxidation in healthy subjects (Basu et al. 2000a), even though pathological alterations were not reported (Basu et al. 2000b). When supplemented independently in high concentration of either the trans-10, cis-12 CLA or the cis-9,trans-11 CLA, these single isomers increased insulin resistance in subjects with the metabolic syndrome (Riserus et al. 2002a, 2004b), whereas the mixture of both isomers did not affect insulin sensitivity of subjects with metabolic syndrome (Riserus et al. 2002a), and improved this in sedentary men (Eyjolfson et al. 2004). To date, only the mixture of both bioactive isomers, but not the high concentrated single isomers, is accessible commercially to all. It was therefore necessary to investigate how supplementation of a commercial mixture of CLA affects blood safety parameters including inflammation and diabetes markers in a long-term study to determine the safety of CLA in human.

The primary objective of the present study was thus to assess the localisation of the BFM reduction in overweight and moderately obese subjects during a 6-month CLA supplementation, and secondarily to determine if CLA supplementation was safe.

\section{Subjects and methods}

\section{Subjects}

A total of 118 healthy male and female volunteers $18-65$ years of age, with BMI of $28-32 \mathrm{~kg} / \mathrm{m}^{2}$, were recruited by two research centres (Diabetes and Overweight Clinic, Specialist Medical Center, Oslo, Norway, n 50; and the Hedmark Medical Center, Hamar, Norway, $n$ 68). All subjects signed an informed consent form before inclusion in the study.

Exclusion criteria included drug therapy, special diet or taking dietary substitutes for weight loss 2 weeks prior to the start of the study. CLA consumption in the form of supplements during the last 3 months prior to the study, pregnant and lactating women, type 1 diabetes or those with untreated type 2 diabetes mellitus, those with a history of hypertension, renal, liver, pancreatic or chronic inflammatory/infectious diseases, cardiac failure or malignant tumours, those with active thyroid disease or receiving thyroid hormone substitution, adrenergic agonist use and volunteers with known/suspected drug or alcohol abuse or with any clinical condition rendering them unfit to participate were also excluded from participation.

\section{Ethics}

The regional Ethics Committee and the local authorities approved the study before it started. The study was conducted in agreement with the Declaration of Helsinki of 1975 as amended in 2000, and in accordance with the International Conference on Harmonization ( $\mathrm{ICH})$ guidelines.

\section{Study design}

This study had a parallel design with two arms, double-blinded, randomised, and placebo-controlled. The subjects were randomised to either CLA $3.4 \mathrm{~g} / \mathrm{d}\left(4.5 \mathrm{~g}\right.$ of Clarinol ${ }^{\mathrm{TM}}$, Lipid Nutrition, Division of Loders Croklaan, The Netherlands, $n$ 59) or placebo (4.5 g of olive oil, $n 59$ ) corresponding to six opaque soft gel capsules, all identical in taste and in appearance. The CLA oil was a mixture containing $37.5 \%$ cis-9, trans -11 and $38 \%$ trans- 10 , cis12. The rest of the mixture was made of other fatty acids (containing $<2 \%$ of trans,trans, $<7 \%$ of saturated fatty acids and $<1 \%$ of NFA). The subjects were on ad libitum diet, and no restrictions in lifestyle or caloric intake were implemented. However, on request, the study nurse gave the subjects dietary advice and exercise recommendations of a general nature at the beginning of the study.

\section{Clinical assessments}

Baseline characteristics and demographic data were recorded by the medical staff when entering the study to evaluate the eligibility of the participants. Smoking habits were divided into four categories (No, Yes: 1-10 cigarettes, 11-19 cigarettes and $\geq 20$ cigarettes per day), whereas alcohol drinking habits were divided into five categories (No, Yes: 1-7 units, $8-14$ units, $15-25$ units and $>25$ units per day) with one unit of alcohol defined as $12 \mathrm{~g}$, or one shot $(30 \mathrm{ml})$, one glass of wine $(12 \mathrm{ml})$ or one glass of beer $(30 \mathrm{ml})$. Weight, BMI and vital signs were recorded every 3 months. Twelvehour fasting blood samples were analysed for adiponectin, alkaline phosphatase (ALP), alanine amino transferase (ALAT), aspartate amino transferase (ASAT), C-reactive protein (CRP), creatinine, erythrocytes, $\gamma$-glutamyltransferase, glucose, glucohaemoglobin (HbAlc), HDL-cholesterol, Hb, leucocytes, LDL-cholesterol, insulin, insulin c-peptide, leptin, lipoprotein a $(\mathrm{Lp}(\mathrm{a}))$, thrombocytes/platelets, total cholesterol, triacylglycerols and white blood cells. All analyses were performed in accredited laboratories (Fürst Laboratory and Aker University Hospital, Oslo, Norway) at baseline and at 6 months. Analsyses of cytokines (interleukin (IL)-1 $\beta$ ), IL-6, IL-8 and tumour necrosis factor- $\alpha$ were performed in a third laboratory (Bioceros, Utrecht, The Netherlands). Compliance was measured every 3 months by counting the returned unused capsules, and compared with the number of capsules that should have been used. A subject was considered compliant when taking $\geq 70 \%$ of the administered supplement.

\section{Adverse events}

An AE was defined as any unfavourable, unintended event (or symptom) reported by a subject or observed by the investigator during the study. All AE were recorded with information about the nature, severity, frequency, onset date, duration and action taken regarding study products. The investigators also classified each $\mathrm{AE}$ as serious or non-serious. A serious $\mathrm{AE}$ was defined as any untoward medical occurrence that resulted in death, was life-threatening, required subject hospitalisation or prolongation of existing hospitalisation, or resulted in persistent or significant disability or incapacity. AE were recorded every 3 months, while serious $\mathrm{AE}$ were monitored continuously throughout the study. The AE did not necessarily 
have a causal relationship with the study product. It was up to the investigators to evaluate the relationship of the AE to the study product in a double blind manner (without code breaking of the randomisation list). Their evaluation was based on previous studies as well as their general practice.

\section{Diet and exercise}

Diet and exercise were assessed at baseline and at 6 months. During about $1 \mathrm{~h}$ prior to the visit to the medical centre, each participant completed diet and exercise forms covering a period of fourteen consecutive days according to a previously evaluated and validated method (Nes et al. 1992). The method provides information on quantity and type of food consumed during the period as described previously (Gaullier et al. 2004), using a specially designed software program BEREGN (Oslo University, Norway). The participation rate was high $(81.7 \%)$, and the non-responders included $n 6$ in the CLA group and $n 14$ in the placebo group. Exercise was assessed as the mean score of the number of training sessions per week with intensity (each subject was categorised according to the following scale: no exercise, score $=0$; exercise 1 time/week without sweat, score $=1$; exercise $2-3$ times/ week without sweat, score $=2$; exercise $>3$ times/week without sweat, score $=3$; exercise 1 time/week with sweat, score $=4$; exercise 2-3 times/week with sweat, score $=5$; exercise $>3$ times/week with sweat, score $=6$ ).

\section{Measurement of body composition, body weight and anthropometric variables}

Dual-energy X-ray absorptiometry (DEXA) was used to determine body composition (Lunar Prodigy, software version 6.0, Madison, WI). Measurements provided masses for the whole body in terms of fat (FBM), muscles and water together as LBM, and bone mineral content (BMC). In addition, regional masses in terms of fat were provided in the arm (AFM), in the abdomen (TFM) and in the legs (LFM).

The Hologic spine phantom was used for daily quality control assessment (CV consistently around $0 \cdot 5 \%$ ). For weekly assessment, the Hologic whole body phantom 162 was used. This phantom has a total weight of $27.8 \mathrm{~kg}$ and consists of five sheets of polyethylene shaped in a pyramidal fashion. In the lower sheet, an aluminium body-shaped figure is embedded and sealed off by a polyvinyl sheet. CV for the surrogates of fat mass, LBM and BMC were $0.7,0.7$ and $0.9 \%$, respectively.

The subjects were weighed on digital scales (TBF-305, Tanita, UK) in their underwear. No subtractions for clothes were performed. Height was measured using wall-fixed Harpenden stadiometers (Holtain, UK) $(\mathrm{CV}<0.2 \%)$. BMI was calculated as the ratio of the weight in $\mathrm{kg}$ by the square of the size expressed in metres. Waist and hip were measured as previously described (Hall \& Young, 1989).

\section{Statistical analysis}

Results are shown as means and standard deviation (SD) (see tables). The primary variable was the change of BFM as determined by DEXA. A test power of $90 \%$ was planned, based on a relative difference in BFM reduction between each CLA group and placebo of at least $1 \times \mathrm{SD}$. Testing between both groups to investigate comparability at baseline was applied using an overall $F$ test. Differences from baseline to month 6 within the groups were tested using a paired $t$ test for normally distributed variables. Categorical variables were analysed using Fisher's exact test or a $\chi^{2}$ test. Comparisons between treatment groups regarding change from baseline in DEXA and weight variable were performed using analysis of covariance, with treatment, centre and gender as factors; baseline value, total energy intake, exercise, and interaction treatment $\times$ energy intake and treatment $\times$ training score as covariates. A significance level of $5 \%$ was used in tests, and all tests were two-tailed. The software used to perform these analyses was SAS for Windows (version 8.2).

Statistical analyses for efficacy and safety parameters were performed on all subjects with at least one post-baseline visit in a subpopulation ( $n$ 105) defined as the intention to treat population. The principle of last-value-carried-forward was applied to this population for efficacy variables only. In addition, statistical analyses for efficacy on the main parameters were performed on the per protocol (PP) population including subjects who completed all visits and with compliance $\geq 70 \%$ ( $n 83)$.

\section{Results}

Study subjects

A total of 118 subjects were randomised and 93 completed the study $(78.8 \%)$, with similar rates of withdrawal in both groups ( $n 12$ for CLA, and $n 13$ for placebo, $P=0 \cdot 37$; Fig. 1). Two subjects in the CLA group discontinued the study because of $\mathrm{AE}$, one left the trial after removal of a malignant breast cancer incidentally discovered, and the other subject suffered from constipation. In the whole population ( $n$ 118), both groups were similar at baseline in gender, age, alcohol use and physical exercise (data not shown).

Out of 118 subjects, thirteen subjects discontinued the study prior to the second visit (month 3 ). Since no data were available for these subjects, they were excluded from all analyses. Both groups had similar baseline characteristics in the remaining population ( $n$ 105; Table 1 ). Compliance at month 6 was $96.7 \%$ (SD 16.7) and $97.8 \%$ (SD 17.1) in the placebo group and in the CLA group, respectively.

Out of the 105 subjects, twelve subjects discontinued the study prior to the third visit (month 6), whereas ten of the remaining subjects had a compliance lower than $70 \%$ as described in the protocol. Therefore, eighty-three subjects completed the study according to the protocol and is defined here as the PP population. Both groups of the PP population

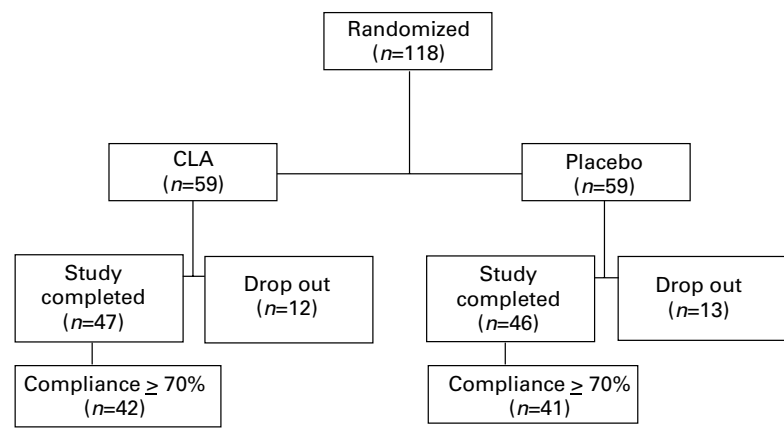

Fig. 1. Study population. 
Table 1. Baseline characteristics of study population (n 105)

\begin{tabular}{|c|c|c|c|c|c|}
\hline & \multicolumn{2}{|c|}{ Placebo (n 50) } & \multicolumn{2}{|c|}{ CLA ( $n 55)$} & \multirow[b]{2}{*}{$P$ value } \\
\hline & Mean & SD & Mean & SD & \\
\hline \multicolumn{6}{|l|}{ Gender } \\
\hline Male & 10 & & 11 & & 1.0 \\
\hline Female & 40 & & 44 & & 0.12 \\
\hline Age (years)* & $48 \cdot 7$ & $9 \cdot 2$ & $45 \cdot 8$ & $10 \cdot 0$ & 0.25 \\
\hline Height $(\mathrm{cm})^{\star}$ & $169 \cdot 7$ & $8 \cdot 1$ & $170 \cdot 0$ & $8 \cdot 8$ & 0.64 \\
\hline Alcohol use (\%)† & $68 \cdot 0$ & & 63.6 & & 0.48 \\
\hline Tobacco use $(\%) \dagger$ & $10 \cdot 0$ & & 14.5 & & 0.54 \\
\hline \multicolumn{6}{|l|}{ Exercise (\%)‡ } \\
\hline No exercise & $26 \cdot 0$ & & $23 \cdot 6$ & & \\
\hline Exercise without sweat & $20 \cdot 0$ & & $23 \cdot 6$ & & \\
\hline Exercise with sweat & $54 \cdot 0$ & & $52 \cdot 7$ & & \\
\hline
\end{tabular}

CLA, conjugated linoleic acid.

*Values for age and height are given as means with their standard deviation, and were recorded within 2 weeks of subjects' inclusion in the study.

†Alcohol and tobacco use are expressed as the percentage of the subjects who answered positively to these questions (\%Yes).

$\ddagger$ Exercise is expressed as the percentage of subjects with no training or training at least once a week at low intensity ( $\%$ without sweating) and high intensity (\% with sweating).

( $n 42$ for CLA and $n 41$ for placebo) were similar at baseline and had compliance at month 6 of $99.2 \%$ (SD 14.6) in the placebo group and $99.2 \%$ (SD 13.3) in the CLA group.

\section{Effects of CLA on body composition}

BFM that did not differ significantly between the groups at baseline $(P=0.69)$ was significantly reduced by $3.4 \%$ after 6 months supplementation with CLA compared with placebo (n 105, $\Delta=-1.2 \mathrm{~kg}, P=0.043$ ) (Table 2). This difference between the groups was also observed when the fat mass was measured as the percentage of the whole body weight ( $n$ 105, $\Delta=-0.9 \%, P=0.028$ ). The decreases in BFM and fat mass percentage were already significantly higher $(n 105$, $\Delta=-0.3 \mathrm{~kg}, P=0.016$ and $\Delta=-0.2 \%, P=0.040$, respectively) in the CLA group as compared with the placebo group after 3 months supplementation. Compared with baseline, the CLA group had significantly reduced BFM at month 6 ( $n 55, \Delta=-1.0 \mathrm{~kg}, P=0.036)$, and body fat percentage ( $n$ 55, $\Delta=-1.0 \%, P=0.009$ ), whereas the BFM and body fat percentage in the placebo group remained unchanged compared with baseline ( $n 50, \Delta=+0.2 \mathrm{~kg}$, $P=0.64$, and $\Delta=-0.1 \%, P=0.77$, respectively; Table 2$)$. CLA was more efficient in women ( $n 84, \Delta=-1.3 \mathrm{~kg}$, $P=0.046)$ than in men ( $n 21, \Delta=-0.7 \mathrm{~kg}, P=0.61)$ when compared with placebo, and more efficient for subjects with $\mathrm{BMI} \geq 30 \mathrm{~kg} / \mathrm{m}^{2}$ ( $\left.n 63, \Delta=-1.3 \mathrm{~kg}, P=0.011\right)$ than for subjects with BMI $<30 \mathrm{~kg} / \mathrm{m}^{2}(n 42, \Delta=-0.3 \mathrm{~kg}, P=0.92)$.

After 6 months supplementation, the difference in LBM between the CLA group and the placebo group was not statistically significant ( $n 105, \Delta=+0.4 \mathrm{~kg}, P=0.22$; Table 2). However, within-group analyses revealed a significant increase in LBM in subjects supplemented with CLA ( $n$ 55, $\Delta=+0.4 \mathrm{~kg}, \quad P=0.049)$, and slight but not significant change in the placebo group ( $n 50, \Delta=+0 \cdot 1 \mathrm{~kg}, P=0.62$; Table 2).

There was no difference in BMC between the groups ( $n$ 105, $P=0.70$; Table 2 ), and no changes within both groups from baseline to month 6 ( $n$ 55 CLA, $P=0 \cdot 36 ; n 50$ placebo, $P=0 \cdot 49)$.

Table 2. Body composition, total and regional fat mass (Mean values and standard deviations)

\begin{tabular}{|c|c|c|c|c|c|c|c|c|c|c|}
\hline \multirow[b]{2}{*}{ Group* } & \multicolumn{2}{|c|}{ Month 0 ( $n$ 105) } & \multicolumn{2}{|c|}{ Month 3 ( $n$ 105) } & \multicolumn{2}{|c|}{ Month 6 ( $n$ 105) } & \multicolumn{2}{|c|}{$\Delta 6-0(n 105)$} & \multicolumn{2}{|c|}{$\Delta 6-0(n 83)$} \\
\hline & Mean & SD & Mean & SD & Mean & SD & Mean & SD & Mean & SD \\
\hline \multicolumn{11}{|l|}{ BFM (\%) } \\
\hline CLA & $42 \cdot 3$ & $6 \cdot 1$ & $42 \cdot 0$ & $6 \cdot 1$ & $41 \cdot 3$ & $6 \cdot 2$ & -1.0 & $2 \cdot 7 \dagger$ & -1.4 & $2 \cdot 8 \dagger$ \\
\hline Placebo & $42 \cdot 2$ & $5 \cdot 6$ & $42 \cdot 1$ & $5 \cdot 7$ & $42 \cdot 1$ & $6 \cdot 1$ & -0.1 & $2 \cdot 2 \ddagger$ & +0.2 & $2 \cdot 0 \ddagger$ \\
\hline \multicolumn{11}{|l|}{ BFM (kg) } \\
\hline CLA & 35.9 & 4.7 & 35.5 & $5 \cdot 1$ & 34.9 & $5 \cdot 7$ & -1.0 & $3.4 \dagger$ & -1.5 & $3 \cdot 6 \dagger$ \\
\hline Placebo & 35.5 & 5.4 & 35.4 & 5.5 & $35 \cdot 7$ & 5.9 & +0.2 & $2 \cdot 3 \ddagger$ & +0.5 & $2 \cdot 2 \ddagger$ \\
\hline \multicolumn{11}{|l|}{ AFM (kg) } \\
\hline CLA & $5 \cdot 1$ & 1.4 & $5 \cdot 1$ & 1.6 & 4.9 & 1.6 & -0.3 & 1.2 & -0.3 & $1 \cdot 2$ \\
\hline Placebo & $5 \cdot 2$ & 1.7 & $5 \cdot 0$ & 1.3 & 4.9 & 1.4 & -0.4 & $1 \cdot 1 \dagger$ & -0.3 & 1.0 \\
\hline \multicolumn{11}{|l|}{ LFM (kg) } \\
\hline CLA & $11 \cdot 2$ & $2 \cdot 8$ & 1.9 & $2 \cdot 6$ & 1.7 & $2 \cdot 7$ & -0.5 & $1.2 \dagger$ & -0.7 & $1.3 \dagger$ \\
\hline Placebo & $11 \cdot 3$ & $2 \cdot 4$ & 11.4 & $2 \cdot 4$ & $11 \cdot 6$ & $2 \cdot 7$ & +0.3 & $1.0 \ddagger$ & +0.3 & $1.0 \ddagger$ \\
\hline \multicolumn{11}{|l|}{ TFM (kg) } \\
\hline CLA & $18 \cdot 6$ & $2 \cdot 4$ & $18 \cdot 6$ & $2 \cdot 5$ & 18.4 & $2 \cdot 9$ & -0.2 & $2 \cdot 0$ & -0.4 & $2 \cdot 2$ \\
\hline Placebo & $18 \cdot 1$ & $2 \cdot 7$ & $18 \cdot 0$ & $2 \cdot 6$ & $18 \cdot 3$ & $2 \cdot 9$ & +0.3 & $1 \cdot 6$ & +0.5 & $1 \cdot 6$ \\
\hline \multicolumn{11}{|l|}{ LBM (kg) } \\
\hline CLA & $49 \cdot 6$ & 9.9 & $49 \cdot 7$ & $9 \cdot 7$ & $5 \cdot 1$ & 9.5 & +0.5 & $1.9 \dagger$ & +0.6 & 1.9 \\
\hline Placebo & $49 \cdot 1$ & 8.4 & $49 \cdot 0$ & $9 \cdot 0$ & $49 \cdot 2$ & $8 \cdot 3$ & +0.1 & 1.4 & +0.2 & 1.5 \\
\hline \multicolumn{11}{|l|}{ BMC (kg) } \\
\hline CLA & $2 \cdot 9$ & 0.5 & 2.9 & 0.5 & 2.9 & 0.5 & 0.0 & 0.1 & 0.0 & 0.1 \\
\hline Placebo & $2 \cdot 8$ & 0.5 & $2 \cdot 8$ & 0.5 & $2 \cdot 8$ & 0.5 & 0.0 & 0.1 & 0.0 & 0.1 \\
\hline
\end{tabular}

BFM, body fat mass; CLA, conjugated linoleic acid; AFM, fat mass in the arms; LFM, fat mass in the legs; TFM, fat mass in the abdomen; LBM, lean body mass, BMC, bone mineral content.

${ }^{*} n 55$ and $n 50$ in the CLA group and placebo group, respectively, in the main population. $n 42$ and $n 41$ in the CLA group and placebo group, respectively, in the per protocol population.

†Difference within the groups between month 6 and month 0 (analysis of variance paired $t$ test, $P<0.05$ ).

$\ddagger$ Difference between the groups (analysis of covariance test, $P<0.05$ ). 
Analyses of the PP population confirmed the analyses obtained for the main population, but in general changes were more pronounced in the PP population (Table 2). In particular, the PP population demonstrated a significant reduction in BFM by $-5.6 \%$ ( $n 83, \Delta=-2.0 \mathrm{~kg}, P=0.005)$ for the CLA group when compared with the placebo group. Reduction of the BFM was already observed after 3 months ( $n$ 42, $\Delta=-0.7 \mathrm{~kg}, P=0.034$ ) in the CLA-supplemented group (data not shown). In the PP population, CLA was also more efficient in women ( $n 65, \Delta=-2.1 \mathrm{~kg}, P=0.005$ ) than in men $(n 18, \Delta=-1 \cdot 1 \mathrm{~kg}, P=0 \cdot 513)$.

\section{Localisation of the decrease in body fat mass}

Fat mass did not differ significantly between the groups at baseline either in the arms ( $n$ 105, AFM, $P=0.83$ ), in the abdomen $(n$ 105, TFM, $P=0.25)$ or in the legs ( $n 105$, LFM, $P=0 \cdot 77$; Table 2). After 6 months of supplementation, the CLA significantly reduced the LFM compared with placebo ( $n 105, \Delta=-0.8 \mathrm{~kg}, P<0.001$ ), but not the ALM ( $n \quad 105, \Delta=+0.1 \mathrm{~kg} \quad P=0.43$ ) nor the TFM ( $n$ 105, $\Delta=-0.5 \mathrm{~kg} P=0.18$; Table 2). Compared with baseline, CLA did not change the AFM $(n 55, \Delta=-0 \cdot 3 \mathrm{~kg}, P=0 \cdot 12)$ or TFM ( $n 55, \Delta=-0 \cdot 2 \mathrm{~kg}, P=0 \cdot 47$ ), but reduced the LFM ( $n 55, \Delta=-0.5 \mathrm{~kg}, P=0.005$ ) at month 6 , while a reduction of AFM ( $n 50, \Delta=-0.4 \mathrm{~kg}, P=0.027$ ) only was observed in the placebo group (Table 2). The reduction of LFM in the CLA group was mainly seen in women $(n 84, \Delta=-1.0 \mathrm{~kg}$, $P<0 \cdot 001)$.
Analyses in the PP population also showed a reduction in LFM which was significantly higher in the CLA group as compared with the placebo group ( $n 83, \Delta=-1.0 \mathrm{~kg}$, $P=0.003)$, and a tendency for a higher reduction in the abdomen ( $n 83, \Delta=-0.9 \mathrm{~kg} P=0.068$; Table 2$)$. In addition, CLA was more efficient in reducing LFM in women ( $n$ 84, $\Delta=-1.2 \mathrm{~kg}, P<0.001)$ and in adults with BMI $\geq 30 \mathrm{~kg} / \mathrm{m}^{2}$ ( $n$ 63, $\Delta=-1.4 \mathrm{~kg}, P<0.001$ ).

\section{Effects of CLA on weight and BMI}

There was no statistical difference between the study groups at baseline either for weight ( $n 105, P=0.63$ ) or for BMI ( $n$ 105, $P=0.25$; Table 3 ). After 6 months of supplementation, there was no significant difference between the groups in weight ( $n$ 105, $\Delta=-0.9 \mathrm{~kg}, P=0 \cdot 15$ ) and BMI $(n 105, \Delta=-0 \cdot 3$, $P=0 \cdot 19$; Table 3 ). Compared with baseline, neither group had changes in body weight ( $n$ 105; CLA, $\Delta=-0.9 \mathrm{~kg}$, $P=0.10$; placebo, $\Delta=0.0 \mathrm{~kg}, P=0.096)$ and BMI ( $n 105$; CLA, $\Delta=-0.3, P=0.07$; placebo, $\Delta=0 \cdot 0, P=0 \cdot 86)$ after 6 months of supplementation (Table 3). However, individuals with a BMI $\geq 30 \mathrm{~kg} / \mathrm{m}^{2}$ lost weight ( $n 63, \Delta=-1.9 \mathrm{~kg}$, $P=0.020$ ) and their BMI decreased significantly (n 63, $\Delta=-0.6, \quad P=0.031)$ after CLA intake compared with placebo.

The PP analyses showed a tendency towards a difference between the groups after 6 months of supplementation in terms of weight ( $n 83, \Delta=-1.5 \mathrm{~kg}, P=0.056)$ and BMI ( $n$ 83, $\Delta=-0 \cdot 6, P=0 \cdot 062$; Table 3). Changes from baseline

Table 3. Body weight, anthropometric measurements, daily caloric intake and exercise measurements (Mean values and standard deviations)

\begin{tabular}{|c|c|c|c|c|c|c|c|c|c|c|}
\hline \multirow[b]{2}{*}{ Group* } & \multicolumn{2}{|c|}{ Month 0 (n 105) } & \multicolumn{2}{|c|}{ Month 3 (n 105) } & \multicolumn{2}{|c|}{ Month 6 (n 105) } & \multicolumn{2}{|c|}{$\Delta 6-0(n 105)$} & \multicolumn{2}{|c|}{$\Delta 6-0(n 83)$} \\
\hline & Mean & SD & Mean & SD & Mean & SD & Mean & SD & Mean & SD \\
\hline \multicolumn{11}{|c|}{ Body weight (kg) } \\
\hline CLA & $88 \cdot 2$ & $9 \cdot 7$ & $87 \cdot 8$ & $1 \cdot 0$ & $87 \cdot 3$ & 1.4 & -0.9 & $3 \cdot 9$ & $-1 \cdot 2$ & $4 \cdot 2$ \\
\hline Placebo & $87 \cdot 4$ & $9 \cdot 8$ & $87 \cdot 7$ & $1 \cdot 3$ & $87 \cdot 4$ & $1 \cdot 1$ & 0.0 & $3 \cdot 3$ & +0.3 & $2 \cdot 3$ \\
\hline \multicolumn{11}{|l|}{ BMI $\left(\mathrm{kg} / \mathrm{m}^{2}\right)$} \\
\hline CLA & 3.5 & $1 \cdot 4$ & 3.4 & $1 \cdot 7$ & $3 \cdot 2$ & $2 \cdot 0$ & -0.3 & $1 \cdot 3$ & -0.5 & $1.5 \dagger$ \\
\hline Placebo & $3 \cdot 2$ & 1.4 & $3 \cdot 4$ & $1 \cdot 6$ & $3 \cdot 2$ & 1.7 & 0.0 & 0.9 & +0.1 & 0.9 \\
\hline \multicolumn{11}{|l|}{ Waist (cm) } \\
\hline CLA & $99 \cdot 3$ & $7 \cdot 5$ & $97 \cdot 4$ & $7 \cdot 5$ & $96 \cdot 6$ & $7 \cdot 4$ & -2.6 & $5.0 \dagger$ & $-3 \cdot 1$ & $5.4 \dagger$ \\
\hline Placebo & 98.5 & $7 \cdot 1$ & $98 \cdot 0$ & $7 \cdot 2$ & $97 \cdot 2$ & $6 \cdot 1$ & $-1 \cdot 3$ & 4.9 & -0.9 & 4.4 \\
\hline \multicolumn{11}{|l|}{ Hip (cm) } \\
\hline CLA & $111 \cdot 1$ & $5 \cdot 0$ & $11 \cdot 1$ & $6 \cdot 0$ & $109 \cdot 7$ & $6 \cdot 2$ & -1.4 & $3.9 \dagger$ & $-1 \cdot 1$ & $4 \cdot 1$ \\
\hline Placebo & 11.5 & 5.5 & $109 \cdot 6$ & $4 \cdot 8$ & $109 \cdot 8$ & $6 \cdot 3$ & -0.6 & 3.8 & -0.6 & $3 \cdot 8$ \\
\hline \multicolumn{11}{|l|}{ Wist-hip ratio } \\
\hline CLA & 0.9 & 0.1 & 0.9 & 0.1 & 0.9 & 0.1 & -0.02 & $0.06 \dagger$ & -0.02 & $0.06 \dagger$ \\
\hline Placebo & 0.9 & $0 \cdot 1$ & 0.9 & 0.1 & 0.9 & 0.1 & -0.01 & $0.05 \ddagger$ & -0.01 & 0.05 \\
\hline \multicolumn{11}{|l|}{ Diet $(k J / d) \S$} \\
\hline CLA & 8825 & 2953 & ND & ND & 7883 & 2940 & -526 & 2242 & -516 & 2273 \\
\hline Placebo & 8893 & 2604 & ND & ND & 7719 & 2204 & -1436 & $2145 \dagger$ & -1421 & $2159 \dagger$ \\
\hline \multicolumn{11}{|l|}{ Exerciseף } \\
\hline CLA (a.u.) & $3 \cdot 27$ & $2 \cdot 24$ & ND & ND & 2.66 & 2.39 & -0.62 & 2.45 & -0.48 & $2 \cdot 36$ \\
\hline Placebo & $3 \cdot 30$ & $2 \cdot 42$ & ND & ND & 2.94 & $2 \cdot 36$ & -0.33 & $2 \cdot 25$ & -0.35 & $2 \cdot 23$ \\
\hline
\end{tabular}

CLA, conjugated linoleic acid; ND, not determined.

${ }^{*} n 55$ and $n 50$ in the CLA group and placebo group, respectively, in the main population. $n 42$ and $n 41$ in the CLA group and placebo group, respectively, in the per protocol population.

†Difference within the groups between month 6 and month 0 (analysis of variance paired $t$ test, $P<0.05$ ).

$\ddagger$ Difference between the groups (analysis of covariance $P<0.05$ ).

$\S$ Diet is expressed as the total energy intake per day.

ๆ Exercise was assessed as the product of the number of training sessions per week with intensity (with or without sweat) and was expressed in arbitrary units (a.u.). 
in the PP population showed a decrease in BMI in the CLA group ( $n 42, \Delta=-0 \cdot 5, P=0 \cdot 040$ ), but not in the placebo group ( $n 41, \Delta=+0 \cdot 1, P=0 \cdot 71)$.

\section{Effects of CLA on anthropometric parameters} of the waist and hip

There was no statistical difference between the study groups ( $n$ 105) at baseline either for waist size $(P=0 \cdot 54)$, hip size $(P=0.54)$ or waist-hip ratio $(P=0.80)$ (Table 3$)$. After 6 months supplementation, there was a higher reduction in the waist-hip ratio in the CLA group as compared with the placebo group ( $n$ 105, $\Delta=-0 \cdot 01, P=0 \cdot 043$; Table 3 ). Compared with baseline, the CLA group ( $n$ 55) had a reduction in waist size $(\Delta=-2.6 \mathrm{~cm}, P<0.001)$, hip size $(\Delta=-1.4, P=0.009)$ and waist-hip ratio $(\Delta=-0.02, P=0.042)$, whereas there were no significant changes within the placebo group ( $n$ 50; waist, $\Delta=-1.3 \mathrm{~cm}, P=0.065$; hip, $\Delta=-0.6 \mathrm{~cm}, P=0.23$; waist-hip ratio, $\Delta=-0 \cdot 01, P=0.27$; Table 3 ).

The analyses in the PP population showed that CLA significantly decreased waist size $(n 42, \Delta=-3.1 \mathrm{~cm}, P<0.001)$ and waist-hip ratio $(n 42, \Delta=-0.02, P=0.018)$, but not hip size $(n 42, \Delta=-1.1 \mathrm{~cm}, P=0.084)$, from baseline to month 6 (Table 3). There was no difference between the groups at month 6 for any of the anthropometric parameters (data not shown).

\section{Diet and exercise}

Caloric intake decreased significantly in the placebo group but not in the CLA group compared with baseline (Table 3). However, there were no differences between the groups either at baseline or after 6 months $(n 105, \Delta=+910 \mathrm{~kJ} / \mathrm{d}, P=0 \cdot 22)$. Physical exercise evaluations remained unchanged between baseline and month 6 within both group (Table 3), and there was no difference between the groups $(n 105, \Delta=+0.29$ arbitrary units, $P=0.73$ ).

The same results were noted in the PP population ( $n$ 83; Table 3).

\section{Safety}

All laboratory parameters were similar between both groups at baseline ( $n$ 105). CLA did not alter clinically any of the following analysed clinical chemistry variables: ALAT $(\Delta=-0.20 \pm 13.64 \mathrm{U} / \mathrm{l}, \quad P=0.92), \quad$ ALP $(\Delta=+2.66 \pm 12.67 \mathrm{U} / \mathrm{l}, P=0.14)$, ASAT $(\Delta=-1.14 \pm 7.91 \mathrm{U} / \mathrm{l}$, $P=0.32)$, creatinine $(\Delta=-14.88 \pm 9.18 \mu \mathrm{mol} / \mathrm{l}, \quad P<0.001$; no difference from the placebo group $P=0.99$ ), erythrocytes $\left(\Delta=-0.06 \pm 0.18 \times 10^{12} / 1, P=0.04\right.$; no difference from the placebo group $P=0.23), \mathrm{Hb}(\Delta=-0.23 \pm 0.60 \mathrm{~g} / 100 \mathrm{ml}$, $P=0.013$; no difference from the placebo group $P=0.42)$ and thrombocytes $\left(\Delta=-3.85 \pm 38.0910^{9} / 1, P=0.27\right)$.

Comparison of the diabetes markers and weight-associated hormones between groups demonstrated no significant differences in changes in fasting glucose $(P=0.40)$, HbA1c $(P=0.28)$, fasting insulin $(P=0.93)$, insulin c-peptide $(P=0.48)$, leptin $(P=0.50)$ and adiponectin $(P=0.72)$ levels (Table 4). After 6 months supplementation with CLA, there were marginal, but significant increases in insulin c-peptide levels $(P=0 \cdot 017)$. However, the increase in insulin c-peptide remained within the normal range. Only one subject in the CLA group and two in the placebo group had an increase in insulin c-peptide level above the normal range values from baseline to 6 months. Glucose $(P<0.001)$ and HbAlc levels $(P=0 \cdot 047)$ decreased compared with baseline. In the placebo group, only glucose levels decreased from baseline to month $6(P<0.001)$ (Table 4).

Comparison of the blood lipids between the groups demonstrated no significant differences in $\operatorname{Lp}(\mathrm{a})(P=0.97)$, total cholesterol $(P=0 \cdot 32)$, HDL cholesterol $(P=0 \cdot 28)$, LDL cholesterol $(P=0 \cdot 19)$ and triacylglycerol $(P=0.22)$ levels (Table 5). After 6 months with CLA supplementation there were also marginal, but significant increases in $\mathrm{Lp}(\mathrm{a})$ levels in both the CLA group $(P=0 \cdot 017)$ and the placebo group $(P=0 \cdot 020)$, whereas HDL cholesterol levels decreased in the CLA group $(P=0.030)$ compared with baseline (Table 5), but these changes remained within the normal range. Twenty subjects with $\mathrm{Lp}$ (a) levels significantly above the normal range at baseline ( $n 13$ and $n 7$ in the CLA group and the placebo group, respectively) maintained or slightly increased their level of $\mathrm{Lp}$ (a) during the study. Finally, one subject from the CLA group had a decrease in HDL cholesterol level to below the normal range at month 6 .

Comparison of the laboratory inflammation markers between groups demonstrated no differences in IL-6 $(P=0.65)$, IL-8 $(P=0.47)$, tumour necrosis factor- $\alpha(P=0.61)$ and leucocyte $(P=0 \cdot 07)$ levels from baseline to month 6 , whereas differences in CRP levels were significantly higher but remained within normal limits in the CLA group compared with the placebo group at month $6(P=0.011)$ (Table 6$)$. IL-1 $\beta$ levels were too low to be detected both at baseline and at month 6 . Six months supplementation with CLA increased CRP levels within the normal range $(P=0.004)$ as compared with baseline, but not the other inflammation markers (Table 6). Three subjects in the CLA group and one subject in the placebo group increased their CRP levels above the normal range at month 6 .

\section{Adverse events}

$\mathrm{AE}$ were reported by $37 \%$ of all randomised subjects, with similar frequencies in both study groups $(P=0 \cdot 85)$. Of 58 single events, the investigators considered five of them related to supplementation ( $n 4$ in the CLA group and $n 1$ in the placebo group) when the study code was still not broken. Of these, one event (diarrhoea) was classified as 'probable' and the rest as 'possible'. All AE were rated as either 'mild' or 'moderate', and were most likely to occur within the gastrointestinal and musculoskeletal systems. The registration of infections reflected a well-known seasonal pattern.

As reported above, two subjects ( $1.7 \%$ of the total) left the trial due to $\mathrm{AE}$, one case of incidentally discovered breast cancer considered unrelated to supplementation, and one case of constipation 'possibly' related to CLA supplementation.

Study supplementation was temporarily interrupted in another three subjects. One male subject suffered an acute myocardial infarction of moderate severity. The serious AE was considered as 'possibly' related to supplementation without breaking the study code. However, the subject rejoined the study a short time after recovery and completed it according to the protocol. After unblinding the study, it was found that the 
Table 4. Laboratory glucose, glucohaemoglobin (HbA1c) and hormone analyses ( $n$ 105) (Mean values and standard deviations)

\begin{tabular}{|c|c|c|c|c|c|c|}
\hline \multirow[b]{2}{*}{ Group* $^{*}$} & \multicolumn{2}{|c|}{ Month 0} & \multicolumn{2}{|c|}{ Month 6} & \multicolumn{2}{|c|}{$\Delta 6-0$} \\
\hline & Mean & SD & Mean & SD & Mean & SD \\
\hline \multicolumn{7}{|c|}{ Glucose (mmol/l) } \\
\hline CLA & 5.56 & 0.72 & $5 \cdot 11$ & 0.57 & -0.48 & $0.81 \dagger$ \\
\hline Placebo & 5.48 & 0.72 & 5.08 & 0.68 & -0.40 & $0.74 \dagger$ \\
\hline \multicolumn{7}{|l|}{$\mathrm{HbA1c}(\%)$} \\
\hline CLA & 5.43 & 0.25 & $5 \cdot 37$ & 0.29 & -0.06 & $0.20 \dagger$ \\
\hline Placebo & 5.45 & 0.29 & $5 \cdot 34$ & 0.27 & -0.10 & $0.21 \dagger$ \\
\hline \multicolumn{7}{|c|}{ Insulin (pmol/l) } \\
\hline CLA & $108 \cdot 6$ & $98 \cdot 3$ & 96.9 & $43 \cdot 2$ & $-3 \cdot 2$ & $33 \cdot 6$ \\
\hline Placebo & 93.6 & $35 \cdot 7$ & $103 \cdot 3$ & $72 \cdot 2$ & $+8 \cdot 7$ & $72 \cdot 3$ \\
\hline \multicolumn{7}{|c|}{ Insulin c-peptide (pmol/l) } \\
\hline CLA & 726.9 & $380 \cdot 3$ & 764.6 & $262 \cdot 0$ & +67.9 & $187 \cdot 4 \dagger$ \\
\hline Placebo & $690 \cdot 4$ & $230 \cdot 4$ & 781.5 & $363 \cdot 1$ & +78.4 & $377 \cdot 4$ \\
\hline \multicolumn{7}{|c|}{ Leptin (pmol/l) } \\
\hline CLA & 1549 & 778 & 1386 & 693 & -82 & 664 \\
\hline Placebo & 1528 & 739 & 1473 & 718 & -3.5 & 490 \\
\hline \multicolumn{7}{|c|}{ Adiponectin (mg/l) } \\
\hline CLA & $11 \cdot 7$ & 4.6 & $11 \cdot 7$ & 4.9 & -0.17 & $2 \cdot 3$ \\
\hline Placebo & $11 \cdot 1$ & $5 \cdot 3$ & $10 \cdot 5$ & 4.9 & -0.32 & $2 \cdot 1$ \\
\hline
\end{tabular}

CLA, conjugated linoleic acid.

Normal range levels are the following: glucose, 3.5-6.0 mmol/l; HbA1c, 5.0-6.0\%; insulin, <200 pmol/l; insulin c-peptide, 220-1400 pmol//; leptin (not defined for these BMI); adiponectin, $4.5-22.4 \mathrm{mg} / \mathrm{l}$.

* In the main population, $n 55$ and $n 50$ in the CLA group and placebo group at month 0 , respectively; $n 50$ and $n 48$ in the CLA group and placebo group at month 6, respectively, for glucose. $n 55$ and $n 50$ in the CLA group and placebo group at month 0 , respectively; and $n$ 49 for both groups at month 6, for HbA1c. $n 55$ and $n 50$ in the CLA group and placebo group at month 0 , respectively; and $n 47$ for both groups at month 6, for insulin, insulin c-peptide, leptin and adiponectin.

†Difference within the groups between month 6 and month 0 (analysis of variance paired $t$ test, $P<0.05$ ).

Table 5. Laboratory blood lipid analyses ( $n$ 105)

(Mean values and standard deviations)

\begin{tabular}{|c|c|c|c|c|c|c|}
\hline \multirow[b]{2}{*}{ Group* } & \multicolumn{2}{|c|}{ Month 0} & \multicolumn{2}{|c|}{ Month 6} & \multicolumn{2}{|c|}{$\Delta 6-0$} \\
\hline & Mean & SD & Mean & SD & Mean & SD \\
\hline \multicolumn{7}{|l|}{$\mathrm{Lp}(\mathrm{a})(\mathrm{mg})$} \\
\hline CLA & 364.3 & 541.9 & $386 \cdot 0$ & $561 \cdot 2$ & $+29 \cdot 6$ & $85.4 \dagger$ \\
\hline Placebo & $257 \cdot 1$ & $281 \cdot 0$ & $280 \cdot 0$ & $316 \cdot 3$ & $+23 \cdot 6$ & $68 \cdot 6 \dagger$ \\
\hline \multicolumn{7}{|c|}{ Total cholesterol $(\mathrm{mmol} / \mathrm{l})$} \\
\hline CLA & $5 \cdot 51$ & $1 \cdot 12$ & $5 \cdot 31$ & $1 \cdot 21$ & $-0 \cdot 18$ & 0.80 \\
\hline Placebo & $5 \cdot 65$ & 1.00 & $5 \cdot 58$ & 1.00 & -0.06 & 0.71 \\
\hline \multicolumn{7}{|c|}{ HDL cholesterol $(\mathrm{mmol} / \mathrm{l})$} \\
\hline CLA & 1.50 & 0.32 & 1.43 & 0.33 & -0.06 & $0.18 \dagger$ \\
\hline Placebo & 1.58 & 0.38 & 1.55 & 0.35 & -0.03 & 0.18 \\
\hline \multicolumn{7}{|c|}{ LDL cholesterol (mmol/l) } \\
\hline CLA & 3.60 & 0.97 & 3.40 & 1.00 & -0.15 & 0.65 \\
\hline Placebo & 3.72 & 0.95 & 3.69 & 0.89 & -0.03 & 0.63 \\
\hline \multicolumn{7}{|c|}{ Triacylglycerol (mmol/l) } \\
\hline CLA & 1.35 & 0.61 & $1 \cdot 34$ & 0.71 & -0.02 & 0.55 \\
\hline Placebo & $1 \cdot 16$ & 0.51 & $1 \cdot 20$ & 0.56 & +0.03 & 0.36 \\
\hline
\end{tabular}

Lp(a), lipoprotein (a); CLA, conjugated linoleic acid; HDL, high-density lipoprotein; LDL, low-density lipoprotein.

Normal range levels are the following: $\mathrm{Lp}(\mathrm{a}),<500 \mathrm{mg} / \mathrm{l}$; total cholesterol, $3.1-8.5 \mathrm{mmol} / \mathrm{l}$; HDL cholesterol, $1.0-2.2 \mathrm{mmol} / \mathrm{l}$ for women and $0.8-2.0 \mathrm{mmol} / \mathrm{l}$ for men; LDL cholesterol, $1.6-5.7 \mathrm{mmol} / /$; triacylglycerol, $<2 \cdot 10 \mathrm{mmol} / \mathrm{l}$.

${ }^{*}$ In the main population, $n 55$ and $n 50$ in the CLA group and placebo group at month 0 , respectively; $n 50$ and $n 49$ in the CLA group and placebo group at month 6 , respectively, for all parameters.

† Difference within the groups between month 6 and month 0 (analysis of variance paired $t$ test, $P<0.05$ ).

subject was supplemented with CLA. The second subject suffered a rash that was not judged related to supplementation. The third subject supplemented with placebo was suffering from a hernia. The investigators chose to reintroduce the three subjects once recovery was established, and all three continued until the scheduled end of the study.

\section{Discussion}

In the present study with overweight and moderately obese subjects, we observed an approximately $3.4 \%$ decrease in BFM after 6 months of supplementation in the main population, and an approximately $5.6 \%$ decrease in BFM in the 
Table 6. Laboratory inflammation analyses ( $n$ 105)

(Mean values and standard deviations)

\begin{tabular}{|c|c|c|c|c|c|c|}
\hline \multirow[b]{2}{*}{ Group* } & \multicolumn{2}{|c|}{ Month 0} & \multicolumn{2}{|c|}{ Month 6} & \multicolumn{2}{|c|}{$\Delta 6-0$} \\
\hline & Mean & SD & Mean & SD & Mean & SD \\
\hline \multicolumn{7}{|l|}{ IL-6 (ng/l) } \\
\hline CLA & 0.31 & 0.15 & 0.43 & 0.41 & +0.14 & 0.41 \\
\hline Placebo & 0.42 & 0.48 & 0.43 & 0.43 & +0.05 & 0.45 \\
\hline \multicolumn{7}{|l|}{ IL-8 (ng/l) } \\
\hline CLA & 3.65 & 1.42 & 4.57 & 4.03 & +0.92 & 3.97 \\
\hline Placebo & $5 \cdot 10$ & 3.41 & 5.99 & 3.02 & +0.94 & 3.63 \\
\hline \multicolumn{7}{|l|}{ TNF- $\alpha(n g / l)$} \\
\hline CLA & 5.96 & 1.68 & 5.96 & 1.41 & 0.00 & 1.62 \\
\hline Placebo & $6 \cdot 21$ & 1.54 & 5.93 & 1.52 & -0.25 & 1.49 \\
\hline \multicolumn{7}{|l|}{ CRP (mg/l) } \\
\hline CLA & 2.93 & $2 \cdot 87$ & 4.46 & 4.81 & +1.46 & $3.43 \dagger$ \\
\hline Placebo & 3.22 & 3.29 & $3 \cdot 14$ & $2 \cdot 71$ & -0.06 & $3.20 \neq$ \\
\hline \multicolumn{7}{|c|}{ Leucocytes $\left(10^{9} / \mathrm{I}\right)$} \\
\hline CLA & 5.95 & 1.62 & $6 \cdot 16$ & 1.55 & +0.21 & $1 \cdot 11$ \\
\hline Placebo & 5.50 & 0.82 & 5.47 & 1.55 & -0.04 & 1.39 \\
\hline
\end{tabular}

IL, interleukin; CLA, conjugated linoleic acid; TNF- $\alpha$, tumour necrosis factor- $\alpha$; CRP, C-reactive protein.

Normal range levels are the following: IL-6, $0.1-10.73 \mathrm{pg} / \mathrm{ml} ; \mathrm{IL}-8,2.5-7.8 \mathrm{pg} / \mathrm{ml}$; TNF- $\alpha, 0-2.1 \mathrm{pg} / \mathrm{ml}$; CRP, $<10 \mathrm{mg} / \mathrm{l}$; leucocytes, $3.3-11.0 \times 10^{9} / \mathrm{l}$

* In the main population, $n 35$ and $n 32$ in the CLA group and placebo group at month 0, respectively; $n 33$ and $n 29$ in the CLA group and placebo group at month 6, respectively, for IL-6. $n 47$ and $n 45$ in the CLA group and placebo group, respectively, at months 0 and 6 for IL-8 and TNF- $\alpha$. $n 55$ and $n 50$ in the CLA group and placebo group at month 0 , respectively, whereas $n 50$ and $n 49$ in the CLA group and the placebo group at month 6 , respectively, for CRP. $n 55$ and $n 50$ in the CLA group and placebo group at month 0, respectively, whereas $n 48$ and $n 49$ in the CLA group and the placebo group at month 6, respectively, for leucocytes.

†Difference within the groups between month 6 and month 0 (analyis of variance paired $t$ test, $P<0.05$ ).

$\ddagger$ Difference between the groups (analysis of covariance test or Wilcoxon test, $P<0.05)$.

PP population compared with placebo. These reductions were thus similar to the reductions observed at 6 months in the previous study performed with CLA containing the same amount of both active isomers trans-10,cis-12 and cis-9,trans-11 (Gaullier et al. 2004). Fat mass might decrease even further up to about $9 \%$ after $1-2$ years as observed previously in overweight subjects (Gaullier et al. 2004, 2005). In addition, the current study confirmed the previous observation (Blankson et al. 2000) indicating that the reduction in BFM was already significant after 3 months of supplementation. In both studies, the best responders were women, and subjects with the highest BMI at the start of the study. However, the efficacy of CLA by gender should be interpreted with care since only one man for every four women participated in these studies, thus reducing the probability of observing small but significant body composition changes in men.

The current study is the first to report that the reduction of BFM occurred mostly in the legs and that CLA had a tendency to decrease the amount of abdominal fat mass, which is in line with the observed significant decrease in the waist-hip ratio. The decrease in fat mass in the legs was observed especially in women, probably due to their gynoid fat distribution (Kirchengast et al. 1998). On the other hand, men (Mueller \& Joos, 1985) and women with several weight loss/regain cycles (Wallner et al. 2004) mostly accumulate fat in the abdomen. In the current study, CLA had a tendency to reduce abdominal fat as supported by a concomitant reduction in the waist-hip ratio. Whereas the clinical importance of the reduction in leg fat mass is unclear and probably does not influence risks of developing CVD in the future (Hara et al. 2004), the reduction in abdominal fat and in the waist-hip ratio may both represent independent indicators of a possible reduction in risks for CVD (Reaven, 2005; Yusuf et al. 2005).

The reduction in BFM was accompanied by maintenance or increase in LBM for a 6-month period in the current study when compared between the groups or within the CLA group, respectively. This LBM may even increase further with time, as seen previously (Gaullier et al. 2004). Loss of fat mass without loss of LBM confers on CLA a unique feature as compared with other weight-reducing agents or physical exercise (Zachwieja et al. 2001; Cox et al. 2003). Maintenance of LBM may help in maintaining energy expenditure, thus preventing regaining body weight, as suggested in our previous study (Gaullier et al. 2005). Lack of effect on body mineral mass does not necessarily mean that CLA does not affect it at all, but it might be that the period of investigation was too short (even though an effect on BMC was not seen in a 2-year study either (Gaullier et al. 2005)) or that variations are under the limits of detection of the DEXA. In addition, susceptible populations with decreased BMC were not investigated in this study.

The present study is the third confirmation in the published literature that CLA supplementation changes body composition in healthy, overweight and/or obese subjects on unrestricted diets and without specific lifestyle restrictions. The reasons why previous studies did not manage to document the efficiency of CLA in body composition may be due either to the use of other and possibly less reliable technologies than the sensitive DEXA technology (Tylavsky et al. 2003), to the use of blends of multiple CLA isomers that are not representative of the 50:50 mixture of the two main isomers used in this study or/and the studies were carried out with not enough power (Berven et al. 2000; Zambell et al. 2000; Noone et al. 2002). Although measurement of regional body composition by DEXA technology is commonly used, questions has been raised concerning the accuracy of measuring changes in abdominal fat mass (Salamone et al. 2000). However, recent publications suggest that this error is very small (Glickman et al. 2004; Woodhouse et al. 2004) and may partly be due to experimental conditions as well as differences in DEXA hardware and software between manufacturers to the advantage of Lunar Prodigy (Soriano et al. 2004; Aasen et al. 2006). In the present study, a high number of participants with a relatively narrow BMI range and measurement under similar conditions on the same apparatus would tend to minimise the importance of this error.

Physical exercise and daily caloric intake, both possible confounders, were not different between the groups either at baseline or after 6 months. In accordance with previous studies (Gaullier et al. 2004, 2005), a modest reduction in caloric intake in both groups (but not significant in the CLA group) was observed during the study. The amount of physical exercise was also slightly reduced, but non-significantly, suggesting that changes in diet or exercise did not play a role in the body composition changes observed during CLA supplementation.

The results of this study confirmed and expanded on the findings of the previous studies: CLA reduces BFM in specific regions of the body and maintains or increases LBM (Berven et al. 2000). 
The mechanism(s) by which CLA decreases BFM and maintains or increases LBM is still an active area of research. It is known that CLA is readily metabolised in tissues of animals and humans where it accumulates and may thus (1) induce adipocyte apoptosis (Evans et al. 2000); (2) inhibit the lipoprotein lipase and increase the carnitine palmitoyltransferase resulting in a reduced accumulation of fatty acids in adipocytes (Park \& Pariza, 2001); (3) bind to peroxisome proliferator-activated receptor- $\gamma$ present in fat tissue and downregulate the expression of leptin (Kallen \& Lazar, 1996), and prevent the accumulation of triacylglycerol in adipocytes (Granlud et al. 2003); or (4) modify energy expenditure and the metabolic rate (West et al. 1998; Terpstra, 2001). In previous studies, leptin levels were shown to reduce according to the BFM reduction (Gaullier et al. 2004, 2005), whereas the leptin levels in the current study did not decrease significantly in the CLA group. However, one subject from the CLA group had, similarly to an increase of weight of $5 \mathrm{~kg}$, an increase in leptin level that might have altered the mean result of leptin in the CLA group. Therefore, the third mechanistic hypothesis involving peroxisome proliferator-activated receptor- $\gamma$ may still be valid.

The current study also corroborated the previous long-term studies with high compliance and low drop-out rates, indicating that CLA supplementation was well tolerated (Gaullier et al. 2004, 2005). A very low percentage of the AE were related to CLA supplementation. These AE were mostly gastrointestinal and musculoskeletal, as observed previously (Vessby \& Smedman, 1999; Blankson et al. 2000; Berven et al. 2000; Thom et al. 2001; Gaullier et al. 2004, 2005). The absence of a difference between the groups indicated that CLA was as safe as olive oil.

None of the blood lipids or inflammatory blood chemical markers were affected except HDL and CRP. A small reduction in HDL and an increase in CRP were observed within the CLA group. However, both changes were within normal ranges. This is in line with earlier findings showing that the CLA 50:50 mixture did not affect CRP levels in healthy subjects and in patients with metabolic syndrome and type 2 diabetes (Riserus et al. 2002b; Moloney et al. 2004; Tricon et al. 2004; Song et al. 2005). Lp(a) and leucocyte levels were not significantly affected in the current study when compared with placebo, which corroborates the findings of three other studies (Berven et al. 2000; Blankson et al. 2000; Moloney et al. 2004). In contrast, two other studies showed an increase in Lp(a) (Gaullier et al. 2004, 2005). Cytokines IL-6, IL-8 and tumour necrosis factor- $\alpha$ were not modified, as observed in two other studies (Riserus et al. 2002b; Ramakers et al. 2005). Furthermore, a previous study has shown that CLA decreases fibrinogen levels in diabetics (Moloney et al. 2004). Thus, taken together, the results suggest that the CLA mixture used in this study does not seem to change the risk for CVD.

It has previously been reported that CLA could induce lipid peroxidation (Basu et al. 2000a,b), and that each of the bioactive CLA isomers could contribute to the increased insulin resistance in subjects with the metabolic syndrome due to increased lipid peroxidation and inflammation (Riserus et al. $2002 a, b, 2004 a, b)$. In the present study, and with the exception of a small increase in insulin c-peptide level within the normal range, all indices of glucose metabolism including fasting glucose and insulin levels were reduced rather than increased, indicating that CLA supplementation was not diabetogenic in this population of overweight and moderately obese subjects at high risk of developing metabolic syndrome or diabetes.

Only appropriately designed long-term studies will unravel the potential benefits of CLA supplementation in obese subjects. We conclude, however, that CLA seems to be safe and well tolerated. The regionalised reduction in fat mass is encouraging and may represent an attractive dietary supplement, especially, but not exclusively, for women with high BMI.

\section{Acknowledgements}

The authors are very grateful to Mette Bogen, clinical nutritionist, who monitored all diet forms and collected data for analysis. Particular thanks to the clinical nurses Bente Ryen, Lill Johannessen and Sissel Paulsen Sundeng for their active contribution to the success of this study. This study was supported by Lipid Nutrition, a Division of Loders Croklaan.

\section{References}

Aasen G, Fagertun H \& Halse J (2006) Body composition analysis by dual X-ray absorptiometry: in vivo and in vitro comparison of three different fan-beam systems. Scand J Clin Lab Invest 66, 659-666.

Akahoshi A, Goto Y, Murao K, Miyazaki T, Yamasaki M, Nonaka M, Yamada K \& Sugano M (2002) Conjugated linoleic acid reduces body fats and cytokine levels of mice. Biosci Biotech Biochem 66, 916-920.

Albers R, van der Wielen R, Brink E, Hendriks H, Dorovska-Taran V \& Mohede I (2003) Effects of cis-9,trans-11 and trans-10,cis-12 conjugated linoleic acid (CLA) isomers on immune function in healthy men. Eur J Clin Nutr 57, 595-603.

Atkinson R (1999) Conjugated linoleic acid for altering body composition and treating obesity In Advances in Conjugated Linoleic Acid Research, Volume 1, pp. 348-353 [M Yurawecz, M Mossoba, J Kramer, M Pariza and G Nelson, editors]. Champaign, IL: AOCS Press.

Bassaganya-Riera J, Pogranichniy RM, Jobgen SC, Halbur PG, Yoon KJ, O'Shea M, Mohede I \& Hontecillas R (2003) Conjugated linoleic acid ameliorates viral infectivity in a pig model of virally induced immunosuppression. J Nutr 133, 3204-3214.

Bassaganya-Riera J, Reynolds K, Martino-Catt S, Cui YZ, Hennighausen L, Gonzalez F, Rohrer J, Benninghoff AU \& Hontecillas R (2004) Activation of PPAR gamma and delta by conjugated linoleic acid mediates protection from experimental inflammatory bowel disease. Gastroenterology 127, 777-791.

Basu S, Riserus U, Turpeinen A \& Vessby B (2000a) Conjugated linoleic acid induces lipid peroxidation in men with abdominal obesity. Clin Sci (Lond) 99, 511-516.

Basu S, Smedman A \& Vessby B (2000b) Conjugated linoleic acid induces lipid peroxidation in humans. FEBS Lett 468, 33-36.

Belury M, Mahon A \& Banni S (2003) The conjugated linoleic acid (CLA) isomer, t10c12-CLA, is inversely associated with changes in body weight and serum leptin in subjects with type 2 diabetes mellitus. J Nutr 133, 257S-260S.

Belury M, Mahon A \& Lingling S (2000) Role of conjugated linoleic acid (CLA) in the management of type 2 diabetes: evidence from Zucker diabetic (fa/fa) rats and human subjects. Abstract, AOCS Meeting, Washington.

Berven G, Bye A, Hals O, Blankson H, Fagertun H, Thom E, Wadstein J \& Gudmundsen O (2000) Safety of conjugated linoleic 
acid (CLA) in overweight or obese human volunteers. Eur J Lipid Sci Technol 102, 455-462.

Bhattacharya A, Rahman MM, Sun DX, Lawrence R, Mejia W, McCarter R, O'Shea M \& Fernandes G (2005) The combination of dietary conjugated linoleic acid and treadmill exercise lowers gain in body fat mass and enhances lean body mass in high fatfed male Balb/C mice. J Nutr 135, 1124-1130.

Blankson H, Stakkestad J, Fagertun H, Thom E, Wadstein J \& Gudmundsen O (2000) Conjugated linoleic acid reduces body fat mass in overweight and obese humans. J Nutr 130, 2943-2948.

Cook M, Miller C, Park Y \& Pariza M (1993) Immune modulation by altered nutrient metabolism: nutritional control of immune-induced growth depression. Poult Sci 72, 1301-1305.

Corino C, Mourot J, Magni S, Pastorelli G \& Rosi F (2002) Influence of dietary conjugated linoleic acid on growth, meat quality, lipogenesis, plasma leptin and physiological variables of lipid metabolism in rabbits. J Anim Sci 80, 1020-1028.

Cox KL, Burke V, Morton AR, Beilin LJ \& Pudley IB (2003) The independent and combined effect of 16 weeks of vigorous exercise and energy restriction on body mass and composition in free-living overweight men - a randomized controlled trial. Metabolism $\mathbf{5 2}$, $107-115$.

Cunningham D, Harrison L \& Shultz T (1997) Proliferative responses of normal human mammary and MCF-7 breast cancer cells to linoleic acid, conjugated linoleic acid and eicosanoid synthesis inhibitors in culture. Anticancer Res 17, 197-203.

DeLany J, Blohm F, Truett A, Scimeca J \& West D (1999) Conjugated linoleic acid rapidly reduces body fat content in mice without affecting energy intake. Am J Physiol 276, R1172-R1179.

Dugan M, Aalhus J, Schaefer A \& Kramer J (1997) The effects of conjugated linoleic acid on fat to lean repartitioning and feed conversion in pigs. Can J Anim Sci 77, 723-725.

Evans M, Geigerman C, Cook J, Curtis L, Kuebler B \& McIntosh M (2000) Conjugated linoleic acid suppresses triglyceride accumulation and induces apoptosis in 3T3-L1 preadipocytes. Lipids $\mathbf{3 5}$, 899-910.

Eyjolfson V, Spriet LL \& Dyck DJ (2004) Conjugated linoleic acid improves insulin sensitivity in young, sedentary humans. Med Sci Sport Exercise 36, 814-820.

Gaullier J-M, Berven G, Blankson H \& Gudmundsen O (2002) Clinical trial results support a preference for using CLA preparations enriched with two isomers rather than four isomers in human studies. Lipids 37, 1019-1025.

Gaullier JM, Halse J, Høye K, Kristiansen K, Fagertun H, Vik H \& Gudmundsen O (2004) Conjugated linoleic acid (CLA) supplementation for one year reduces body fat mass in healthy, overweight humans. Am J Clin Nutr 79, 1118-1125.

Gaullier JM, Halse J, Høye K, Kristiansen K, Fagertun H, Vik H \& Gudmundsen O (2005) Supplementation with conjugated linoleic acid for 24 months is well tolerated by and reduces body fat mass in healthy, overweight humans. J Nutr 135, $778-784$

Gavino V, Gavino G, Leblanc M \& Tuchweber B (2000) An isomeric mixture of conjugated linoleic acids but not pure cis-9, trans-11octadecadienoic acid affects body weight gain and plasma lipids in hamsters. J Nutr 130, 27-29.

Glickman SG, Marn CS, Supiano MA \& Dengel DR (2004) Validity and reliability of dual-energy X-ray absorptiometry for the assessment of abdominal adiposity. $J$ Appl Physiol 97, 509-514.

Granlud L, Juvet L, Pedersen J \& Nebb H (2003) Trans 10, cis 12 conjugated linoleic acid prevents triacylglycerol accumulation in adipocytes by acting as a PPARgamma modulator. J Lipid Res 44, 1441-1452.

Hall TR \& Young TB (1989) A validation study of body fat distribution as determined by self-measurement of waist and hip circumference. Int J Obes 13, 801-807.
Hara M, Saikawa T, Kurokawa M, Sakata T \& Yoshimatsu H (2004) Leg fat percentage correlates negatively with coronary atherosclerosis. Circ J 68, 1173-1178.

Houseknecht K, Vanden Heuvel J, Moya-Camarena S, Portocarrero C, Peck L, Nickel K \& Belury M (1998) Dietary conjugated linoleic acid normalizes impaired glucose tolerance in the Zucker diabetic fatty fa/fa rat. Biochem Biophys Res Commun 244, 678-682.

Ip C, Singh M, Thompson H \& Scimeca J (1994) Conjugated linoleic acid suppresses mammary carcinogenesis and proliferative activity of the mammary gland in the rat. Cancer Res 54, 1212-1215.

Kallen CB \& Lazar MA (1996) Antidiabetic thiazolidinediones inhibit leptin ob gene expression in 3T3-L1 adipocytes. Proc Natl Acad Sci USA 93, 5793-5796.

Kirchengast S, Gruber D, Sator M, Knogler W \& Huber J (1998) The impact of nutritional status on body fat distribution patterns in preand postmenopausal females. J Biosoc Sci 30, 145-154.

Kreider R, Ferreira M, Greenwood M, Wilson M \& Almada A (2002) Effects of conjugated linoleic acid supplementation during resistance-training on body composition, bone density, strength, and selected hematological markers. J Strength Cond Res 3, 325-334.

Lee K, Kritchevsky D \& Pariza M (1994) Conjugated linoleic acid and atherosclerosis in rabbits. Atherosclerosis 108, 19-25.

Liew C, Schut H, Chin S, Pariza M \& Dashwood R (1995) Protection of conjugated linoleic acids against 2-amino-3-methylimidazo[4,5f]quinoline-induced colon carcinogenesis in the F344 rat: a study of inhibitory mechanisms. Carcinogenesis 16, 3037-3043.

Lowery L, Appicelli P \& Lemon P (1998) Conjugated linoleic acid enhances muscle size and strength gains in novice bodybuilders. (Abstract 1038). Med Sci Sports Exerc 30, 182.

Miller C, Park Y, Pariza M \& Cook M (1994) Feeding conjugated linoleic acid. Biochem Biophys Res Commun 198, 1107-1112.

Moloney F, Yeow TP, Mullen A, Nolan JJ \& Roche HM (2004) Conjugated linoleic acid supplementation, insulin sensitivity, and lipoprotein metabolism in patients with type 2 diabetes mellitus. Am J Clin Nutr 80, 887-895.

Mueller WH \& Joos SK (1985) Android (centralized) obesity and somatotypes in men: association with mesomorphy. Ann Hum Biol 12, 377-381.

Nes M, Andersen L, Solovoll K, Sandstad B, Hustvedt B, Løvø A \& Drevon C (1992) Accuracy of a quantitative food frequency questionnaire applied in elderly Norwegian women. Eur J Clin Nutr 46, 809-821.

Nicolosi R, Rogers E, Kritchevsky D, Scimeca J \& Huth P (1997) Dietary conjugated linoleic acid reduces plasma lipoproteins and early aortic atherosclerosis in hypercholesterolemic hamsters. Artery 22, 266-277.

Noone E, Roche H, Nugent A \& Gibney M (2002) The effect of dietary supplementation using isomeric blends of conjugated linoleic acid on lipid metabolism in healthy human subjects. $\mathrm{Br} J \mathrm{Nutr}$ 88, 243-251.

Ostrowska E, Suster D, Muralitharan M, Cross RF, Leury BJ, Bauman DE \& Dunshea FR (2003) Conjugated linoleic acid decreases fat accretion in pigs: evaluation by dual-energy X-ray absorptiometry. Br J Nutr 89, 219-229.

Park Y, Albright K, Storkson J, Liu W, Cook M \& Pariza M (1999) Changes in body composition in mice during feeding and withdrawal of conjugated linoleic acid. Lipids 34, 243-248.

Park Y \& Pariza M (2001) Lipoxygenase inhibitors inhibit heparinreleasable lipoprotein lipase activity in 3T3-L1 adipocytes and enhance body fat reduction in mice by conjugated linoleic acid. Biochim Biophys Acta 1534, 27-33.

Rahman S, Wang Y, Han S, Cha J, Fukuda N, Yotsumoto H \& Yanagita T (2001) Effects of short-term administration of conjugated linoleic acid on lipid metabolism in white and brown adipose tissues of starved/refed Otsuka Long-Evans Tokushima Fatty rats. Food Res Int 34, 515-520. 
Ramakers JD, Plat J, Sebedio JL \& Mensink RP (2005) Effects of the individual isomers cis- 9 , trans- 11 vs. trans-10, cis-12 of conjugated linoleic acid (CLA) on inflammation parameters in moderately overweight subjects with LDL-phenotype B. Lipids $\mathbf{4 0}$, 909-918.

Reaven G (2005) All obese individuals are not created equal: insulin resistance is the major determinant of cardiovascular disease in overweight/obese individuals. Diab Vasc Dis Res 2, 105-112.

Riserus U, Arner P, Brismar K \& Vessby B (2002a) Treatment with dietary trans10cis12 conjugated linoleic acid causes isomerspecific insulin resistance in obese men with the metabolic syndrome. Diabetes Care 25, 1516-1521.

Riserus U, Basu S, Jovinge S, Fredrikson G, Arnlov J \& Vessby B (2002b) Supplementation with conjugated linoleic acid causes isomer-dependent oxidative stress and elevated C-reactive protein: a potential link to fatty acid-induced insulin resistance. Circulation 106, 1925-1929.

Riserus U, Berglund L \& Vessby B (2001) Conjugated linoleic acid (CLA) reduced abdominal adipose tissue in obese middle-aged men with signs of the metabolic syndrome: a randomised controlled trial. Int J Obes Relat Metab Disord 25, 1129-1135.

Riserus U, Vessby B, Arner P \& Zethelius B (2004a) Supplementation with trans10cis12-conjugated linoleic acid induces hyperproinsulinaemia in obese men: close association with impaired insulin sensitivity. Diabetologia 47, 1016-1019.

Salamone LM, Fuerst T, Visser M, Kern M, Lang T, Dockrell M, Cauley JA, Nevitt M, Tylavsky F \& Lohman T (2000) Measurement of fat mass using DEXA: a validation study in elderly adults. J Appl Physiol 89, 345-352.

Schonberg S \& Krokan H (1995) The inhibitory effect of conjugated dienoic derivatives (CLA) of linoleic acid on the growth of human tumor cell lines is in part due to increased lipid peroxidation. Anticancer Res 15, 1241-1246.

Song HJ, Grant I, Rotondo D, Mohede I, Sattar N, Heys SD \& Wahle KW (2005) Effect of CLA supplementation on immune function in young healthy volunteers. Eur J Clin Nutr 59, 508-517.

Soriano JM, Ioannidou E, Wang J, Thornton JC, Horlick MN, Gallagher D, Heymsfield SB \& Pierson RN (2004) Pencil-beam vs fan-beam dual-energy X-ray absorptiometry comparison across four systems: body composition and bone mineral. J Clin Densitom 7, 281-289.

Szymczyk B, Pisulewski P, Szczurek W \& Hanczakowski P (2001) Effects of conjugated linoleic acid on growth performance, feed conversion efficiency, and subsequent carcass quality in broiler chickens. Br J Nutr 85, 465-473.

Terpstra A (2001) Differences between humans and mice in efficacy of the body fat lowering effect of conjugated linoleic acid: role of metabolic rate. J Nutr 131, 2067-2068.

Thom E, Wadstein J \& Gudmundsen O (2001) Conjugated linoleic acid reduces body fat in healthy exercising humans. $J$ Int Med Res 29, 392-396.
Tricon S, Burdge GC, Kew S, Banerjee T, Russell JJ, Grimble RF, Williams CM, Calder PC \& Yaqoob P (2004) Effects of cis-9,trans-11 and trans-10,cis-12 conjugated linoleic acid on immune cell function in healthy humans. Am J Clin Nutr 80, 1626-1633.

Tylavsky FA, Lohman TG, Dockrell M, Lang T, Schoeller DA, Wan JY, Fuerst T, Cauley JA, Nevitt M \& Harris TB (2003) Comparison of the effectiveness of 2 dual-energy X-ray absorptiometers with that of total body water and computed tomography in assessing changes in body composition during weight change. Am J Clin Nutr 77, 356-363.

Vessby B \& Smedman A (1999) Conjugated linoleic acid (CLA) reduces the body fat content in humans. Abstract Section, Chemistry and Physics of Lipids 101, 141-213. Abstract T2/01, P. 152.

Wallner SJ, Luschnigg N, Schnedl WJ, Lahousen T, Sudi K, Crailsheim K, Möller R, Taifet E \& Horejsi R (2004) Body fat distribution of overweight females with a history of weight cycling. Int J Obes Relat Metab Disord 28, 1143-1148.

Wargent E, Sennit MV, Stocker C, et al. (2005) Prolonged treatment of genetically obese mice with conjugated linoleic acid improves glucose tolerance and lowers plasma insulin concentration: possible involvement of PPAR activation. Lipids Health Dis 4, 3.

West D, DeLany J, Camet P, Blohm F, Truett A \& Scimeca J (1998) Effects of conjugated linoleic acid on body fat and energy metabolism in the mouse. Am J Physiol 275, R667-R672.

Whigham LD, O'Shea M, Mohede ICM, Walaski HP \& Atkinson RL (2004) Safety profile of conjugated linoleic acid in a 12-month trial in obese humans. Food Chem Toxicol 42, 1701-1709.

Wong M, Chew B, Wong T, Hosick H, Boylston T \& Shultz T (1997) Effects of dietary conjugated linoleic acid on lymphocyte function and growth of mammary tumors in mice. Anticancer Res 17, 987-993.

Woodhouse LJ, Gupta N, Bhasin M, Singh AB, Ross R, Phillips J \& Bhasin S (2004) Dose-dependent effects of testosterone on regional adipose tissue distribution in healthy young men. J Clin Endocrinol Metab 89, 718-726.

Yusuf S, Hawken S, Ounpuu S, et al. (2005) Obesity and the risk of myocardial infarction in 27,000 participants from 52 countries: a case-control study. Lancet 366, 1640-1649.

Zachwieja JJ, Ezell DM, Cline AD, Ricketts JC, Vicknair PC, Schorle SM \& Ryan DH (2001) Short-term dietary energy restriction reduces lean body mass but not performance in physically active men and women. Int J Sports Med 22, 310-316.

Zambell K, Keim N, Van Loan M, Gale B, Benito P, Kelley D \& Nelson G (2000) Conjugated linoleic acid supplementation in humans: effects on body composition and energy expenditure. Lipids 35, 777-782.

Zu H \& Schut H (1992) Inhibition of 2-amino-3-methylimidazo[4,5f]quinoline-DNA adduct formation in CDF1 mice by heat-altered derivatives of linoleic acid. Food Chem Toxicol 30, 9-16. 